\title{
PREDIÇÃO DE PRESSÕES DE SATURAÇÃO DE COMPONENTES PRESENTES NA OBTENÇÃO DO BIODIESEL
}

\author{
A. SOUZA ${ }^{1}$, P.F. ARCE CASTILLO ${ }^{1}$ \\ ${ }^{1}$ Universidade de São Paulo, Escola de Engenharia de Lorena \\ E-mail para contato: andressasouza@usp.br
}

\begin{abstract}
RESUMO - As pressões de saturação são propriedades termodinâmicas utilizadas para testar a eficiência de uma equação de estado, principalmente ao se tratar de substâncias de massa molar alta, como é o caso dos componentes presentes na produção de biodiesel. O objetivo principal deste trabalho de pesquisa foi verificar o desempenho da equação de estado de Peng-Robinson na predição de pressões de saturação de componentes presentes na obtenção do biodiesel e também realizar uma comparação entre os resultados calculados com essa equação de estado e os obtidos pelo método de redes neurais artificiais. Os cálculos realizados com a equação de estado Peng-Robinson em MS Excel se mostraram relativamente precisos para a maioria dos componentes estudados neste artigo, exceto para o glicerol, em que houve um desvio médio de pressão de saturação de $19,5 \% \mathrm{em}$ relação a dados de pressão experimentais, e para a trioleína, com erros ainda maiores, enquanto o método de redes neurais artificiais se mostrou mais eficiente. Paralelamente foi desenvolvida uma interface gráfica para predizer as pressões de saturação de vários componentes utilizando MatLab-GUI.
\end{abstract}

\section{INTRODUÇÃO}

\subsection{Biodiesel}

O biodiesel é um combustível de origem renovável composto por ésteres de ácidos graxos de cadeia longa derivados de óleos vegetais ou gorduras animais. Ele libera menores quantidades de monóxido de carbono quando comparado com o diesel obtido do petróleo e é constituído de carbono neutro, ou seja, sua obtenção e queima não contribuem para o aumento das emissões de dióxido de carbono na atmosfera. Por isso, o biodiesel é considerado um combustível ecologicamente correto e possui grande potencial para substituir a utilização de combustíveis fósseis, sendo que atualmente já se realizam misturas de até $20 \%$ de biodiesel em diesel convencional, uma vez que eles possuem características físico-químicas semelhantes (Mariano, 2012).

\subsection{Redes Neurais Artificiais (RNA)}

Uma rede neural artificial é um sistema computacional constituído por unidades conhecidas como neurônios, que são unidades de processamento interligadas que trabalham em paralelo para executar uma determinada tarefa. A RNA é uma importante técnica 
estatística não-linear utilizada para resolver uma série de problemas complexos, principalmente os que envolvem classificação de padrões e previsão de dados (Vellasco, 2007). O modo de funcionamento de uma rede neural artificial se assemelha ao cérebro, pois o conhecimento é adquirido a partir de seu ambiente por meio de um processo de aprendizagem. Além disso, o processo de armazenamento do conhecimento adquirido é realizado pelos pesos sinápticos, que são as forças de conexão entre os neurônios. Desse modo, a aprendizagem faz com que a RNA modifique sua matriz de pesos sinápticos e se adapte até que ela consiga um algoritmo de execução, que é construído utilizando os exemplos com que a rede neural foi treinada (Zupan e Gasteiger, 1993).

\section{MODELO TERMODINÂMICO}

Uma ferramenta fundamental para o cálculo de propriedades termodinâmicas específicas de uma determinada substância é a representação precisa da relação entre pressão, volume específico e temperatura. Essa relação pode ser expressa de diferentes modos, sendo que as formulações analíticas, que se utilizam das equações de estado, são as mais utilizadas (Moran e Shapiro, 2012). Segundo Terron (2009), atualmente na termodinâmica química existe uma grande quantidade de equações de estado que podem ser utilizadas no cálculo de propriedades termodinâmicas, por exemplo, as propriedades de equilíbrio de substâncias puras e misturas, como pressão de saturação e fugacidade.

\subsection{Equação de Estado de Peng-Robinson}

A equação de Peng-Robinson é uma equação cúbica de estado que correlaciona propriedades termodinâmicas e, portanto, pode ser utilizada para predizer propriedades de interesse tanto de substâncias puras quanto de misturas (Peng e Robinson, 1976). Ela é expressa em termos de P, v e T conforme a Equação 1:

$$
P=\frac{R T}{v-b}-\frac{a}{v(v+b)+b(v-b)}
$$

em que $\mathrm{P}$ corresponde à pressão do sistema, $\mathrm{R}$ é a constante universal dos gases, $\mathrm{T}$ é a temperatura absoluta, $\mathrm{v}$ é o volume molar e a e b são parâmetros dependentes das propriedades críticas do componente i, conforme descrito nas Equações 2 e 3 :

$$
\begin{aligned}
& a=0,45724 \frac{R^{2} T_{c, i}^{2}}{P_{c, i}} \alpha(T) \quad, \quad b=0,07780 \frac{R T_{c, i}}{P_{c, i}} \\
& \alpha(T)=\left[1+m_{i}\left(1-\sqrt{T_{R_{i} i}}\right)\right]^{2}, \quad m_{i}=0,37464+1,54226 w_{i}-0,26992 w_{i}^{2}
\end{aligned}
$$

em que $T_{c}$ é a temperatura crítica, $T_{R}$ é a temperatura reduzida, $P_{c}$ é a pressão crítica e $w$ é o fator acêntrico.

A equação de estado de Peng-Robinson (EdE PR) também pode ser expressa em termos do fator de compressibilidade (z), como visto na Equação 4:

$$
z^{3}-(1-B) z^{2}+\left(A-2 B-3 B^{2}\right) z-A B+B^{2}+B^{3}=0
$$

com as constantes adimensionais A e B calculadas pelas seguintes equações: 


$$
A=\frac{a P}{R^{2} T^{2}} \quad, \quad B=\frac{b P}{R T}
$$

A Equação 4 apresenta três raízes, sendo que se elas forem reais, a menor raiz positiva corresponde ao fator de compressibilidade do líquido saturado e a maior raiz representa o fator de compressibilidade do vapor saturado. Se houver apenas uma raiz real, o sistema podese encontrar no estado de líquido comprimido ou vapor superaquecido.

\section{METODOLOGIA}

Neste trabalho foi utilizado o software MS Excel e a EdE Peng-Robinson para determinar o equilíbrio de fases: $\phi^{\mathrm{L}}=\phi^{\mathrm{V}}$ (Terron, 2009), onde os " $\phi$ ", os chamados coeficientes de fugacidade, nas fases líquida e vapor foram obtidos utilizando a Equação 6:

$$
\ln \hat{\phi}=(z-1)-\ln (z-B)+\frac{A}{2 \sqrt{2} B} \ln \left[\frac{z+(1-\sqrt{2}) B}{z+(1+\sqrt{2}) B}\right]
$$

onde z é o fator de compressibilidade e A e B são as constantes adimensionais da EdE PR.

Para isso, foram utilizadas as propriedades críticas e os fatores acêntricos dos componentes presentes na obtenção do biodiesel. A equação de Antoine e suas respectivas constantes para cada substância foi utilizada para estimar a pressão de saturação experimental dos componentes.

No equilíbrio acontece a igualdade entre os coeficientes de fugacidades das fases líquida e vapor, sendo assim, a ferramenta Solver foi utilizada para encontrar essa condição minimizando a função objetivo $(\mathrm{FO}):\left|\mathrm{f}^{\mathrm{L}} / \mathrm{f}^{\mathrm{V}}-1\right|$, de tal forma que o solver mudou os valores iniciais de chute de pressão de saturação em cada temperatura para atingir o valor mínimo dessa FO. O desvio padrão relativo entre os valores obtidos com a EdE PR e os valores experimentais foi calculado de acordo com a Equação 7:

$$
\text { Desvio }=\frac{\left|P_{\text {calc }}-P_{\text {exp }}\right|}{P_{\text {exp }}} * 100
$$

em que $\mathrm{P}_{\text {calc }}$ é a pressão de saturação calculada e $\mathrm{P}_{\exp }$ é a pressão de saturação experimental à mesma temperatura.

Por outro lado, foi feita a predição das pressões de saturação (variável dependente) utilizando redes neurais artificiais (RNA) tendo como variáveis independentes as propriedades críticas, o fator acêntrico e a temperatura de saturação. Foram estudadas várias arquiteturas do tipo $\mathrm{X}-\mathrm{X}-1$ e $\mathrm{X}-\mathrm{X}-\mathrm{X}-1$ onde $\mathrm{X}$ representam o número de neurônios em cada arquitetura ou camadas utilizando a rotina de otimização de Levenberg-Marquardt.

\section{RESULTADOS E DISCUSSÃO}

Os dados de propriedades dos pontos triplo e crítico e do fator acêntrico para os componentes utilizados nesse trabalho estão dispostos na Tabela 1. Durante a realização dos cálculos para cada componente, verificou-se que o recurso Solver não foi capaz de calcular a 


\section{Congresso Brasileiro de Engenharia Química \\ em Iniciação Científica \\ UFSCar - São Carlos - SP \\ 16 a 19 de Julho de 2017}

CONGRESSO BRASILEIRO DE ENGENHARIA

pressão de saturação para substâncias como o oleato de metila e a trioleína, devido a uma limitação desse recurso em realizar cálculos precisos envolvendo iterações. Sendo assim, para estes componentes utilizou-se uma interface gráfica desenvolvida em MatLab-GUI para a determinação da pressão de saturação, uma vez que esse software é mais eficiente e preciso em cálculos iterativos.

Tabela 1 - Pressão e temperatura do ponto triplo e do ponto crítico e fator acêntrico de alguns componentes presentes na produção do biodiesel.

\begin{tabular}{|c|c|c|c|c|c|}
\hline \multirow{2}{*}{ Componente } & \multicolumn{2}{|c|}{ Ponto Triplo } & \multicolumn{2}{c|}{ Ponto Crítico } & Fator \\
\cline { 2 - 4 } & $\mathrm{T}(\mathrm{K})$ & $\mathrm{P}(\mathrm{bar})$ & $\mathrm{T}(\mathrm{K})$ & $\mathrm{P}($ bar $)$ & Acêntrico $(\mathrm{w})$ \\
\hline $\mathrm{CO}_{2}$ & 216,58 & 5,1867 & 304,20 & 72,10 & 0,225 \\
\hline Metanol & 175,47 & $1,11 * 10^{6}$ & 512,50 & 80,84 & 0,566 \\
\hline Etanol & 159,05 & $4,96^{*} 10^{-9}$ & 513,90 & 61,49 & 0,649 \\
\hline Água & 273,16 & 0,006113 & 647,29 & 220,90 & 0,344 \\
\hline Glicerol & 291,33 & 0,00001 & 850,00 & 75,00 & 0,516 \\
\hline Ácido Caproico & 269,25 & $2,67 * 10^{-6}$ & 666,70 & 33,89 & 0,706 \\
\hline Ácido Láurico & 316,98 & $2,58^{*} 10^{-6}$ & 736,50 & 18,89 & 0,988 \\
\hline Ácido Palmítico & 335,66 & $2,93 * 10^{-7}$ & 777,10 & 14,89 & 1,176 \\
\hline Oleato de Metila & 293,05 & 0,00001 & 764,00 & 12,80 & 1,049 \\
\hline Dodecanoato de Metila & 278,15 & $6,12 * 10^{7}$ & 712,00 & 17,46 & 0,730 \\
\hline Trioleina & 278,15 & 0,00016 & 1640,00 & 4,70 & 1,600 \\
\hline
\end{tabular}

Fontes: DIPPR, 2000; Terron, 2009.

Após a obtenção dos valores de desvio entre dados calculados e experimentais de pressão de saturação, observou-se que o cálculo da pressão de saturação do glicerol utilizando o MS Excel e o recurso Solver gerou um valor de desvio médio alto (cerca de 28\%), sendo assim, para esse componente também foi utilizado o MatLab para obter resultados mais precisos. Já para a trioleína, mesmo utilizando a interface em MatLab-GUI, foram obtidos desvios extremamente grandes, de modo que esse resultado foi desconsiderado deste trabalho. Isso pode ter ocorrido devido à trioleína possuir uma alta massa molar e também por suas propriedades nos pontos triplo e crítico ainda não terem sido bem definidas. Para melhor organização dos resultados obtidos, fez-se a média dos desvios relativos dos pontos utilizados para cada componente, apresentados na Tabela 2. É possível notar que os desvios relativos obtidos com a EdE PR em grande maioria foram relativamente pequenos. Segundo Terron (2009), uma equação de estado é precisa quanto menores forem os desvios observados entre os valores calculados com ela e valores experimentais nas mesmas condições de temperatura e pressão. Logo, verifica-se que a EdE PR se mostrou precisa na predição da pressão de saturação de grande parte dos componentes presentes na produção do biodiesel.

Os valores de desvio mais altos em alguns componentes podem ser explicados por certa limitação da equação de Peng-Robinson em regiões de temperatura e pressão baixas, que são encontradas próximas ao ponto triplo. Os valores muito pequenos de pressão de saturação também afetam o cálculo do desvio padrão (Equação 7) já que mesmo que o valor calculado se aproxime do valor experimental, o desvio calculado nesse caso será grande. Outra possível explicação seria uma limitação própria do software Excel e do recurso Solver em realizar cálculos iterativos para valores muito pequenos. Sendo assim, seria mais adequado realizar a predição da pressão de saturação desses componentes no MatLab, uma vez que este software 
apresenta resultados mais precisos. A interface gráfica desenvolvida em MatLab-GUI (Graphical Unit Interface) se mostra na Figura 1.

Tabela 2 - Desvio relativo médio entre dados de pressão de saturação de diferentes componentes calculados pela EdE PR e RNA.

\begin{tabular}{|c|c|c|}
\hline \multirow{2}{*}{ Componente } & \multicolumn{2}{|c|}{ Desvio Relativo (\%) } \\
\cline { 2 - 3 } & EdE PR & RNA \\
\hline \hline $\mathrm{CO}_{2}$ & 2,83 & 0,56 \\
\hline Metanol & 6,20 & 0,80 \\
\hline Etanol & 3,35 & 0,68 \\
\hline Água & 6,36 & 1,56 \\
\hline Glicerol & 19,50 & 2,34 \\
\hline Ácido Caproico & 8,87 & 1,22 \\
\hline Ácido Láurico & 12,95 & 2,32 \\
\hline Ácido Palmítico & 6,89 & 0,86 \\
\hline Oleato de Metila & 8,82 & 0,58 \\
\hline Dodecanoato de Metila & 1,86 & 0,18 \\
\hline Trioleína & ---- & 3,28 \\
\hline
\end{tabular}

Figura 1 - Predição das pressões de saturação de componentes presentes na obtenção do biodiesel através da interface gráfica desenvolvida em MatLab-GUI.

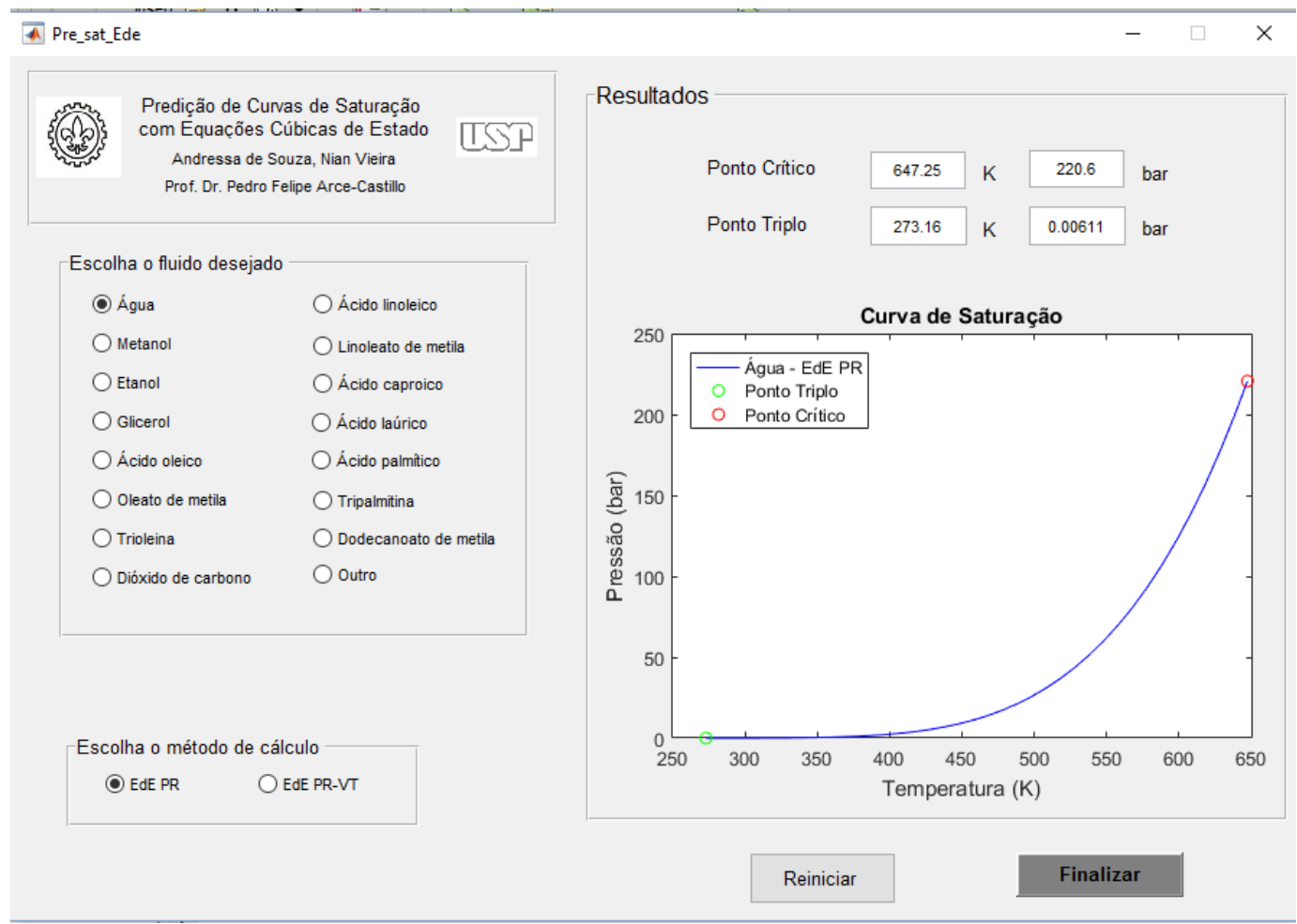

Em relação ao método de redes neurais artificiais, a melhor arquitetura da RNA foi a de 3 camadas, do tipo 5-5-1, onde o "1" representa a variável dependente (pressão de saturação) e as variáveis independentes selecionadas foram as propriedades críticas, fator acêntrico e 0 
ponto triplo (pressão e temperatura). O método de otimização utilizado na simulação com a RNA foi de Levenberg-Marquardt. Em trabalhos anteriores, essa função se apresentou como a mais eficiente quando comparada com as outras funções de otimização implementadas no MatLab. Ao analisar os resultados, nota-se que com a RNA foram obtidos os menores valores de desvio, além de ser possível realizar o cálculo das pressões de saturação para a trioleína com maior precisão que a EdE PR e o Solver do MS Excel.

\section{CONCLUSÃO}

Verificou-se que a predição da pressão de saturação de componentes presentes na produção de biodiesel utilizando a EdE PR foi boa com resultados satisfatórios, considerando que há certa limitação dessa EdE em pontos próximos ao ponto triplo das substâncias. Concluiu-se que os resultados obtidos com o software MatLab apresentam desvios menores entre os valores de pressão de saturação calculados e os valores experimentais. Além disso, o método de rede neural artificial se apresenta como uma ferramenta rápida e eficiente para ser aplicada na Termodinâmica, não apenas para a predição de propriedades termodinâmicas assim como também na predição da modelagem termodinâmica do equilíbrio fases líquidovapor e líquido-líquido, como já verificado por um dos autores deste trabalho.

\section{REFERÊNCIAS}

DIPPR Information and Data Evaluation Manager. Version 1.2.0, 2000.

MARIANO, G. C. Produção de biodiesel supercrítico a partir de semente de soja via processo não catalítico. 2012. 170 f. Tese (Doutorado em Engenharia Química) - Centro Tecnológico, UFSC, Florianópolis.

MORAN, M. J.; SHAPIRO, H. N. Princípios da Termodinâmica para Engenharia. 6. ed. Rio de Janeiro: LTC, 2012.

PENG, D. Y.; ROBINSON, D. B. A new two constant equation of state. Ind. Eng. Chem. Fundam., v. 15, p. 59-64, 1976.

TERRON, L. R. Termodinâmica Química Aplicada. 1. ed. São Paulo: Manole, 2009.

VELLASCO, M. M. B. R. Redes Neurais Artificiais. Pontifícia Universidade Católica do Rio de Janeiro, 2007.

ZUPAN, J.; GASTEIGER, J. Neural Networks for Chemists. Nova Iorque: VCH Publishers, 1993.

\section{AGRADECIMENTOS}

A. Souza agradece à Escola de Engenharia de Lorena (EEL) da Universidade de São Paulo (USP) pela oportunidade de realizar sua primeira Iniciação Científica e P.F. Arce Castillo agradece à Fundação de Amparo à Pesquisa do Estado de São Paulo (FAPESP) pelo auxílio financeiro à pesquisa (processo 2015/05155-8). 